\title{
Experimental Research on Key Factors Influencing the Expansion Performance of New Type Sealing Materials
}

\author{
Yaobin Li $\mathbb{D},{ }^{1}$ Xin Guo $\mathbb{D}^{1},{ }^{1}$ Sheng Xue $\mathbb{D}^{1},{ }^{1}$ Chun-Shan Zheng $\mathbb{D}^{1}{ }^{1}$ Maoliang Shen $\mathbb{D},{ }^{1}$ \\ and Yang $X u \mathbb{D}^{2}$ \\ ${ }^{1}$ School of Safety Science and Engineering, Anhui University of Science and Technology, Huainan 232001, Anhui, China \\ ${ }^{2}$ College of Horticulture Science and Engineering, Fujian Agricultural University, Fuzhou 350000, Fujian, China
}

Correspondence should be addressed to Xin Guo; guoxin190510@163.com

Received 8 September 2021; Accepted 15 December 2021; Published 30 December 2021

Academic Editor: Chunchi Ma

Copyright (c) 2021 Yaobin Li et al. This is an open access article distributed under the Creative Commons Attribution License, which permits unrestricted use, distribution, and reproduction in any medium, provided the original work is properly cited.

\begin{abstract}
To improve the borehole sealing effect, especially that of coal seam with low permeability and micro fissures, this paper takes the expansion rate of the sealing material as the response value and establishes the quadratic model embracing the expansion rate and various experimental factors by designing orthogonal experiments. The response surface is used to further determine the significance order of each key factor according to the expansion rate and adjust the admixture content to obtain the optimal ratio of the sealing material. For the research investigating a sealing material, the optimal ratio of the sealing material is obtained: the content of water reducing agent of $0.5 \%$, the content of retarder of $0.04 \%$, water-cement ratio of 0.8 , and the content of expansion agent of $10 \%$. At this time, the expansion rate reaches $3.136 \%$. Besides, a scanning electron microscope is used to observe the microscopic morphology of the material. According to the scanning electron microscopy analysis of new borehole sealing materials, the surface of the new borehole sealing material shows no holes and possesses compactness; and a large amount of ettringite is formed on the surface of the hydration product of hardened cement slurry. The ettringite improves the expansibility of the material. The new sealing material provides a new idea for gas sealing, which is of great significance to improve the efficiency of borehole extraction, improve the utilization rate of resources, and prevent gas accidents.
\end{abstract}

\section{Introduction}

Gas disasters and accidents frequently occur in China and seriously affect production safety in coal mines. With the consumption of coal resources, China is facing increasingly serious gas problems $[1,2]$. Currently, the commonly used gas control measure is gas drainage, and the sealing material is one of the critical factors to ensure the drainage effect. The common sealing materials of coal mines in China include cement mortar and polyurethane materials. However, the cement mortar materials will shrink after curing, resulting in cracks and air leakage [3-6]. Polyurethane materials are expensive and toxic.

To solve these problems, many scholars have studied the optimization of sealing materials. Some scholars have developed a CF type expansive cement composed of ordinary Portland cement, aluminum powder, $\mathrm{CaO}$, and gypsum. The expansive cement with good fluidity and high compressive capacity optimizes the expansion performance of cement materials [7, 8]. Hogancamp and Grasley [9] have found that carbon nanofibers can increase the shrinkage and improve the expansion ratio of ultrafine cement mortar while maintaining the hardness. Wang et al. [10] have mixed ordinary cement, coal gangue powder, and clay in a certain proportion for a new type of grouting sealing material, whose compressive strength and expansion ratio can be significantly improved. Liu et al. [11] studied the effect of different expansive agents on the expansion properties of cement slurry. Ye et al. [12] have compared the effects of calcium sulfoaluminate-calcium oxide and magnesium oxide on the expansion rate of Portland cement and found that calcium sulfoaluminate-calcium oxide increases the early strength, while magnesium oxide improves the expansion rate at the middle and late stage. Some scholars have studied 
the effect of sulfate on the early hydration and hardening of Portland cement. Sulfate accelerates the hydration at all times [13, 14]. Feng et al. [15] studied the effect of magnesium oxide expansive agent on self-healing of early cracks in concrete. Some scholars have studied the influencing factors of $\mathrm{MgO}$ expansive agent effect, which provides a direction for the improvement of expansion performance of sealing materials $[16,17]$. Zhou and Wang [18] have studied the influence of the amount of dispersant and expansion agent on the new sealing material based on the compressive strength and expansion ratio and finally determined the optimal ratio of each factor.

At present, the research of improving sealing materials has made remarkable achievements but mostly focusing on enhancing the grouting effect on large fissures. There is little research on the grouting effect on micro fissures. This study focuses on curing cracking of cement materials and the poor grouting effect on micro fissures. Design-Expert software is used to design an orthogonal experiment, draw a response surface graph, and take the expansion rate of the material as the index to optimize the ratio of the sealing material. Finally, the scanning electron microscope is used to analyze the microstructure of the material and the expansion mechanism is studied.

\section{Experimental Materials}

The new type of borehole sealing material with a gray appearance is based on ultrafine Portland cement, and its composition is provided in Table 1 . All technical parameters and indicators have met the requirements of "Superfine Portland Cement" (GB/T35161-2017). The expansion agent is HCSA with an appearance of off-white powder. The water-reducing agent is PCE with white powder. The retarder used in this experiment is seaweed powder with a white appearance.

\section{Experimental Method}

29 groups of experiments with four factors and three levels were designed using Box-Behnken experiment design function in Design-Expert 8.0.5 software. The value ranges of the experimental factors are shown in Table 2.

Firstly, the standard triple trial mold was prepared. Secondly, according to the ratio in Table 2, the dry material quality and water quality required for the production of the specimens were calculated. Thirdly, the ultrafine cement and the admixture were mixed thoroughly (as shown in Figure 1) by adding water. Finally, after molding and then demolding (as shown in Figure 2), the specimens were put into the curing box for curing (temperature of $20 \pm 2^{\circ} \mathrm{C}$, humidity above $95 \%$, as shown in Figure 3).

The well-mixed cement slurry was poured into the round mold in the fluidity test of sealing material. After the surface was scraped, the round mold was quickly lifted. The round mold is $60 \mathrm{~mm}$ in height with an upper mouth diameter of $36 \mathrm{~mm}$ and a low mouth diameter of $60 \mathrm{~mm}$. After the flowing of the cement slurry, the two diameters perpendicular to each other were measured, and the average value was used as the fluidity.

The measurement of setting time refers to the test method for water consumption of the material with standard cement consistency, setting time, and stability (GB/T13462011). The setting time was measured by the Vicat apparatus. Firstly, the Vicat apparatus was made zero. Then the mixed material was poured into the test mold. After that, the surface of the material was scraped and the material was put into the curing box for curing. Finally, the initial and final setting times were measured according to national standards.

The material's initial volume after molding and demolding was recorded as $V_{1}$, and then the volumes at intervals were recorded as $V_{n}$. The expansion rate of this experimental study is the expansion rate after curing for 60 days, according to the expansive Cement Expansion Rate Test Method (JC_T 313-2009). The expansion rate was calculated according to the following formula:

$$
\varepsilon_{t}=\frac{V_{n}-V_{1}}{V_{1}} \times 100 \% \text {, }
$$

where $V_{n}$ is the volume of the specimen at a certain age and $V_{1}$ is the initial volume of the specimen.

The compressive strength test of the sample utilizes the RMT uniaxial press to test the compressive strength of stones of different ages (Figure 4).

After obtaining the optimal ratio of admixtures through orthogonal experiments, firstly, the specimens with the ultrafine cement material and admixture are prepared according to the optimal ratio. Secondly, the ZEISS scanning electron microscope was used to analyze the hydration mineral composition, hydration degree, and microstructure of cement-based materials. Finally, the action mechanism of new sealing materials was studied.

\section{Experimental Results and Discussion}

4.1. Orthogonal Experiment Results and Response Surface Analysis. In the practical application, it is necessary to comprehensively consider the compressive strength, fluidity, and expansion rate and optimize the multiobjective nonlinear formula to determine the optimal ratio. According to the results of the orthogonal experiment in Table 3, watercement ratio, retarder dosage, water reducer dosage, and expansion agent dosage were set as independent variables $\mathrm{A}$, $\mathrm{B}, \mathrm{C}$, and $\mathrm{D}$. The expansion ratio was taken as the objective function for multiple variables nonlinear regression fitting and response surface analysis.

The results of the orthogonal experiment (shown in Table 3) were inputted into the Design-Expert 8.0.5 Trial software to find the most suitable model. The fitting results are shown in Tables 4 and 5. It can be seen from Table 4 that the linear equation and the quadratic equation model have a larger $F$ value and a smaller Prob $>F$ value, indicating that the two fitting models are the most suitable ones. It can be seen from Table 5 that the sum of squares of prediction residuals is low in several models. The $R 2$ value of the 
TABLE 1: Chemical composition of raw materials.

\begin{tabular}{|c|c|c|c|c|c|c|c|c|}
\hline Chemical composition & $w\left(\mathrm{SiO}_{2}\right)$ & $w\left(\mathrm{Al}_{2} \mathrm{O}_{3}\right)$ & $w\left(\mathrm{Fe}_{2} \mathrm{O}_{3}\right)$ & $w(\mathrm{CaO})$ & $w(\mathrm{MgO})$ & $w\left(\mathrm{SO}_{3}\right)$ & Loss & Total \\
\hline HCSA expanding agent & 4.96 & 8.52 & 0.99 & 64.18 & 2.67 & 16.97 & 1.19 & 99.48 \\
\hline Superfine Portland cement & 20.57 & 9.89 & 3.08 & 57.65 & 2 & 2.7 & 2.6 & 98.49 \\
\hline
\end{tabular}

TABLE 2: Range of factors in the orthogonal experiment.

\begin{tabular}{lcccc}
\hline \multirow{2}{*}{ Test group } & \multicolumn{3}{c}{ Value range of each factor/\% } \\
& Water-cement ratio & Retarder & Water-reducing agent & Expanding agent \\
\hline ZJ1-29 & $0.8 \sim 1.0$ & $0.03 \sim 0.05$ & $0.3 \sim 0.5$ & $8-10$ \\
\hline
\end{tabular}

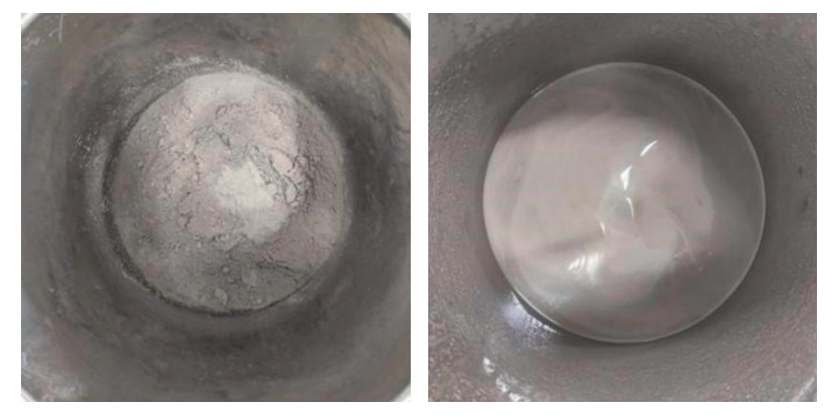

FIgURE 1: Sealing material before and after mixing.
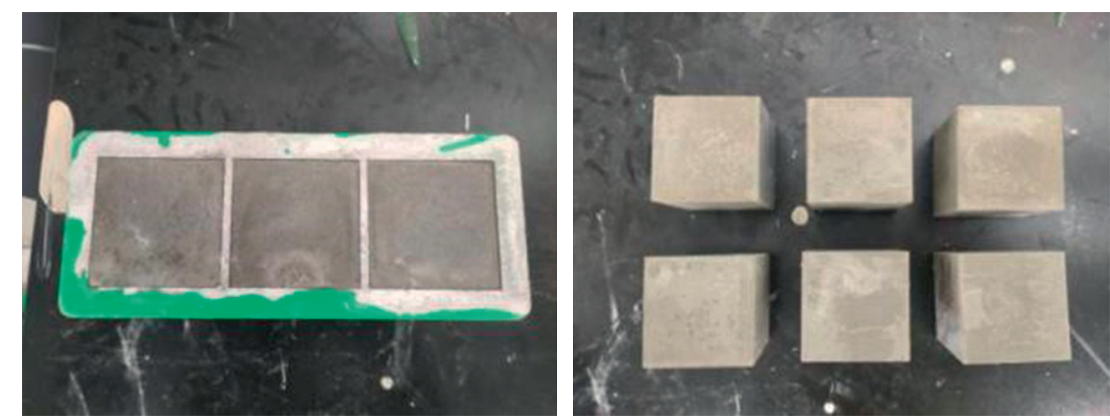

Figure 2: Preparation of specimens.

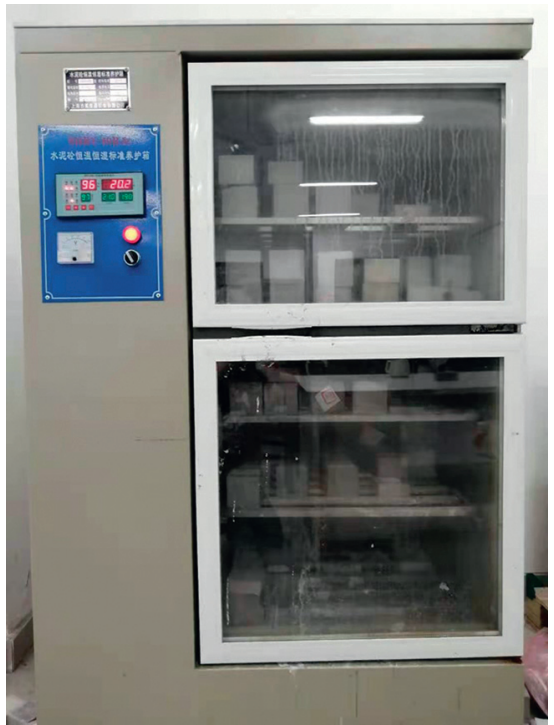

Figure 3: Curing of the specimens. quadratic model (0.9052) is closer to 1 . Besides, Adj. $R^{2}$ of the linear model is smaller than that of the quadratic equation model, indicating that the linear model needs further improvement.

4.2. Variance Results and Significance Tests. From Table 6, it can be seen that the significance order of the factors is as follows: D (expansion agent) $>\mathrm{A}$ (water-cement ratio) $>\mathrm{C}$ (water-reducing agent) $>\mathrm{B}$ (retarder). The order of interaction of different factors is as follows: $\mathrm{AD}$ (water-cement ratio, expansion agent) $>\mathrm{CD}$ (water-reducing agent, expansion agent) $>\mathrm{BD}$ (retarder, expansion agent) $>\mathrm{AC}$ (water-cement ratio, water-reducing agent) $>\mathrm{BC}$ (retarder, water-reducing agent)) $>\mathrm{AB}$ (water-cement ratio, retarder).

4.3. Response Surface Analysis. The interaction law was also obtained by analyzing the interaction of any two factors. Figure 5 shows the effect of retarder [19] and expansion agent [20] on the expansion rate. It can be seen that the 


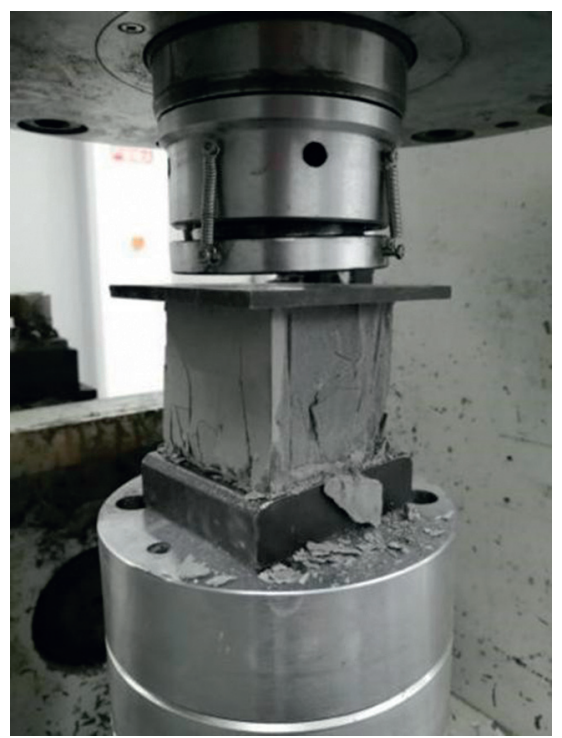

Figure 4: Compressive strength test.

TABLE 3: Results of orthogonal test.

\begin{tabular}{|c|c|c|c|c|c|}
\hline No. & $\mathrm{A}$ & $\mathrm{B} / \%$ & $\mathrm{C} / \%$ & $\mathrm{D} / \%$ & Expansion rate/\% \\
\hline 1 & 0.8 & 0.03 & 0.4 & 9 & 1.897 \\
\hline 2 & 0.8 & 0.04 & 0.5 & 9 & 2.032 \\
\hline 3 & 0.8 & 0.04 & 0.4 & 10 & 3.281 \\
\hline 4 & 0.8 & 0.04 & 0.3 & 9 & 1.931 \\
\hline 5 & 0.8 & 0.04 & 0.4 & 8 & 1.593 \\
\hline 6 & 0.8 & 0.05 & 0.4 & 9 & 1.821 \\
\hline 7 & 0.9 & 0.03 & 0.5 & 9 & 1.898 \\
\hline 8 & 0.9 & 0.03 & 0.4 & 10 & 2.471 \\
\hline 9 & 0.9 & 0.03 & 0.4 & 8 & 1.614 \\
\hline 10 & 0.9 & 0.03 & 0.3 & 9 & 1.521 \\
\hline 11 & 0.9 & 0.04 & 0.4 & 9 & 2.053 \\
\hline 12 & 0.9 & 0.04 & 0.4 & 9 & 2.053 \\
\hline 13 & 0.9 & 0.04 & 0.3 & 10 & 2.329 \\
\hline 14 & 0.9 & 0.04 & 0.4 & 9 & 2.053 \\
\hline 15 & 0.9 & 0.04 & 0.5 & 8 & 1.589 \\
\hline 16 & 0.9 & 0.04 & 0.5 & 10 & 2.809 \\
\hline 17 & 0.9 & 0.04 & 0.3 & 8 & 1.621 \\
\hline 18 & 0.9 & 0.04 & 0.4 & 9 & 2.053 \\
\hline 19 & 0.9 & 0.04 & 0.4 & 9 & 2.053 \\
\hline 20 & 0.9 & 0.05 & 0.3 & 9 & 1.621 \\
\hline 21 & 0.9 & 0.05 & 0.5 & 9 & 1.812 \\
\hline 22 & 0.9 & 0.05 & 0.4 & 10 & 2.597 \\
\hline 23 & 0.9 & 0.05 & 0.4 & 8 & 1.531 \\
\hline 24 & 1 & 0.04 & 0.3 & 9 & 1.986 \\
\hline 25 & 1 & 0.03 & 0.4 & 9 & 1.778 \\
\hline 26 & 1 & 0.04 & 0.4 & 10 & 2.093 \\
\hline 27 & 1 & 0.05 & 0.4 & 9 & 1.803 \\
\hline 28 & 1 & 0.04 & 0.4 & 8 & 1.302 \\
\hline 29 & 1 & 0.04 & 0.5 & 9 & 1.889 \\
\hline
\end{tabular}

contours of the ordinate are denser than those of the abscissa, indicating that the effect on the response value of the expansion agent is more significant than that of the water-cement ratio. The response surface is relatively steep, indicating that the interaction between the water-cement ratio and the expansive agent is prominent. The most obvious interaction occurs when the water-cement ratio reaches the low limit, and the expansion agent reaches the upper limit, which is shown as the steepest response surface.

Figure 6 shows the effect of the water-reducing agent [21-23] and the expansion agent on the expansion rate. It can be seen that the ordinate contours are denser than the abscissa contours, indicating that the expansion agent has a 
TABLE 4: Analysis of variance of different models.

\begin{tabular}{lccccc}
\hline Source & Sum of squares & $\mathrm{df}$ & Mean square & $F$ value & $p$ value Prob $>F$ \\
\hline Mean versus total & 112.36 & 1 & 112.36 & & 18.18 \\
Linear & 3.67 & 4 & 0.92 & 0.98 & 0.0001 \\
2FI & 0.30 & 6 & 0.050 & 3.40 & 0.4653 \\
Quadratic & 0.45 & 4 & 0.11 & 5.63 & 0.0247 \\
Cubic & 0.41 & 8 & 0.051 & & Suggested \\
Residual & 0.054 & 6 & $9.061 \times 10^{-3}$ & & \\
Total & 117.24 & 29 & 4.04 & & \\
\hline
\end{tabular}

TABLE 5: Comprehensive statistical analysis of multiple models.

\begin{tabular}{lccccc}
\hline Source & Std. dev & $R$-squared & Adjusted $R$-squared & Predicted $R$-squared & PRESS \\
\hline Linear & 0.22 & 0.7519 & 0.7106 & 0.6149 & 1.88 \\
2FI & 0.23 & 0.8131 & 0.7093 & 0.3961 & 2.95 \\
Quadratic & 0.18 & 0.9052 & 0.8105 & 0.4542 & 2.66 \\
Cubic & 0.095 & 0.9889 & 0.9480 & -0.6049 & 7.83 \\
\hline
\end{tabular}

TABle 6: Response surface quadratic model and ANOVA results.

\begin{tabular}{|c|c|c|c|c|c|}
\hline Source & Sum of squares & $\mathrm{df}$ & Mean square & $F$ & Prob $>F$ \\
\hline Model & 4.42 & 14 & 0.32 & 9.55 & $<0.0001$ \\
\hline A & 0.24 & 1 & 0.24 & 7.33 & 0.0170 \\
\hline B & $3.000 \times 10^{-6}$ & 1 & $3.000 \times 10^{-6}$ & $9.086 \times 10^{-5}$ & 0.9925 \\
\hline $\mathrm{C}$ & 0.087 & 1 & 0.087 & 2.63 & 0.1274 \\
\hline $\mathrm{D}$ & 3.34 & 1 & 3.34 & 101.13 & $<0.0001$ \\
\hline $\mathrm{AB}$ & $2.550 \times 10^{-3}$ & 1 & $2.550 \times 10^{-3}$ & 0.077 & 0.7851 \\
\hline $\mathrm{AC}$ & $9.801 \times 10^{-3}$ & 1 & $9.801 \times 10^{-3}$ & 0.30 & 0.5944 \\
\hline $\mathrm{AD}$ & 0.20 & 1 & 0.20 & 6.09 & 0.0271 \\
\hline $\mathrm{BC}$ & $8.649 \times 10^{-3}$ & 1 & $8.649 \times 10^{-3}$ & 0.26 & 0.6168 \\
\hline $\mathrm{BD}$ & 0.011 & 1 & 0.011 & 0.33 & 0.5743 \\
\hline $\mathrm{CD}$ & 0.066 & 1 & 0.066 & 1.98 & 0.1807 \\
\hline $\mathrm{A} 2$ & 0.017 & 1 & 0.017 & 0.52 & 0.4819 \\
\hline B2 & 0.21 & 1 & 0.21 & 6.49 & 0.0232 \\
\hline $\mathrm{C} 2$ & 0.062 & 1 & 0.062 & 1.87 & 0.1931 \\
\hline $\mathrm{D} 2$ & 0.10 & 1 & 0.10 & 3.14 & 0.0981 \\
\hline Residual & 0.46 & 14 & 0.033 & & \\
\hline Lack of fit & 0.46 & 10 & 0.046 & & \\
\hline Pure error & 0.000 & 4 & 0.000 & & \\
\hline Cor total & 4.88 & 28 & & & \\
\hline
\end{tabular}
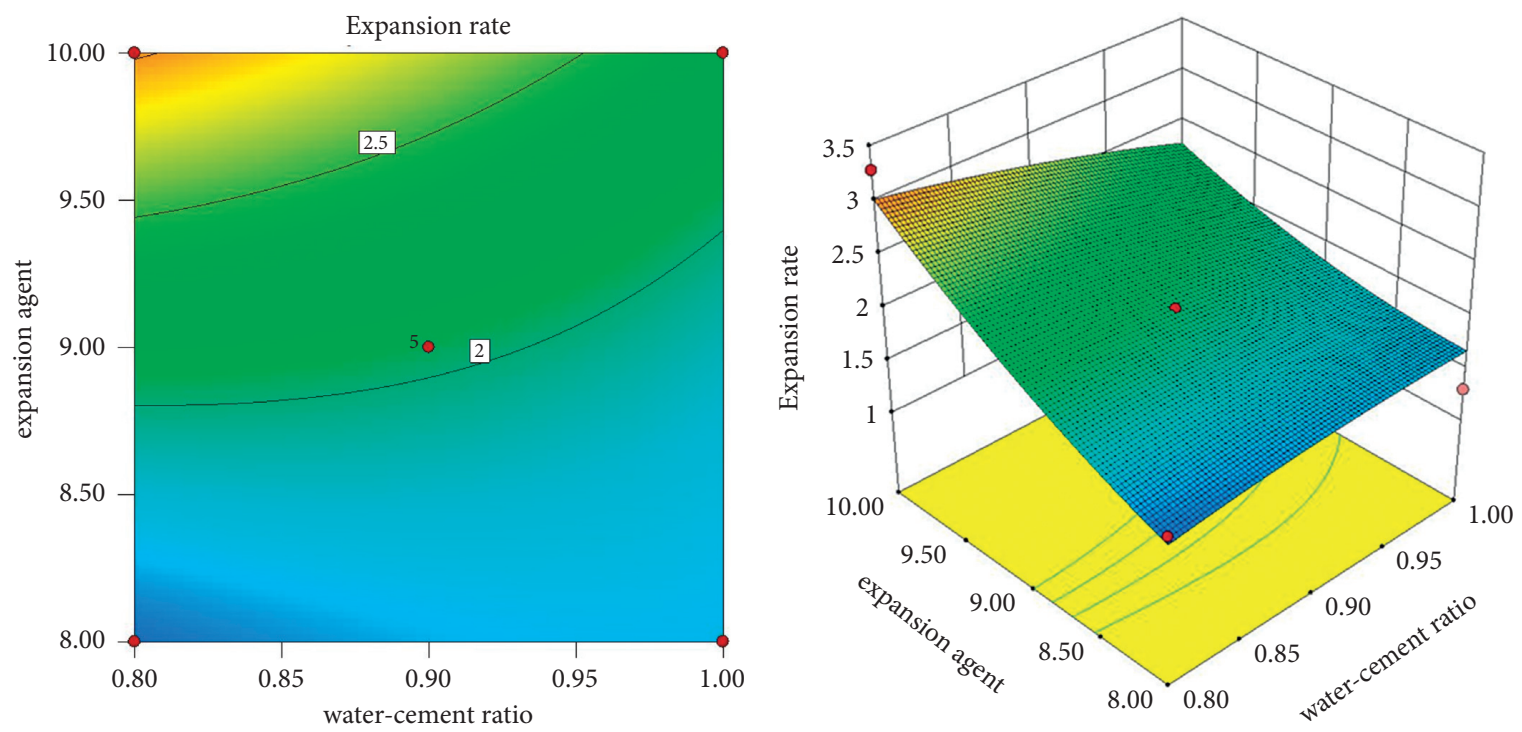

Figure 5: Effect of the water-cement ratio $\mathrm{A}$ and expansion agent $\mathrm{D}$ on the expansion rate. 

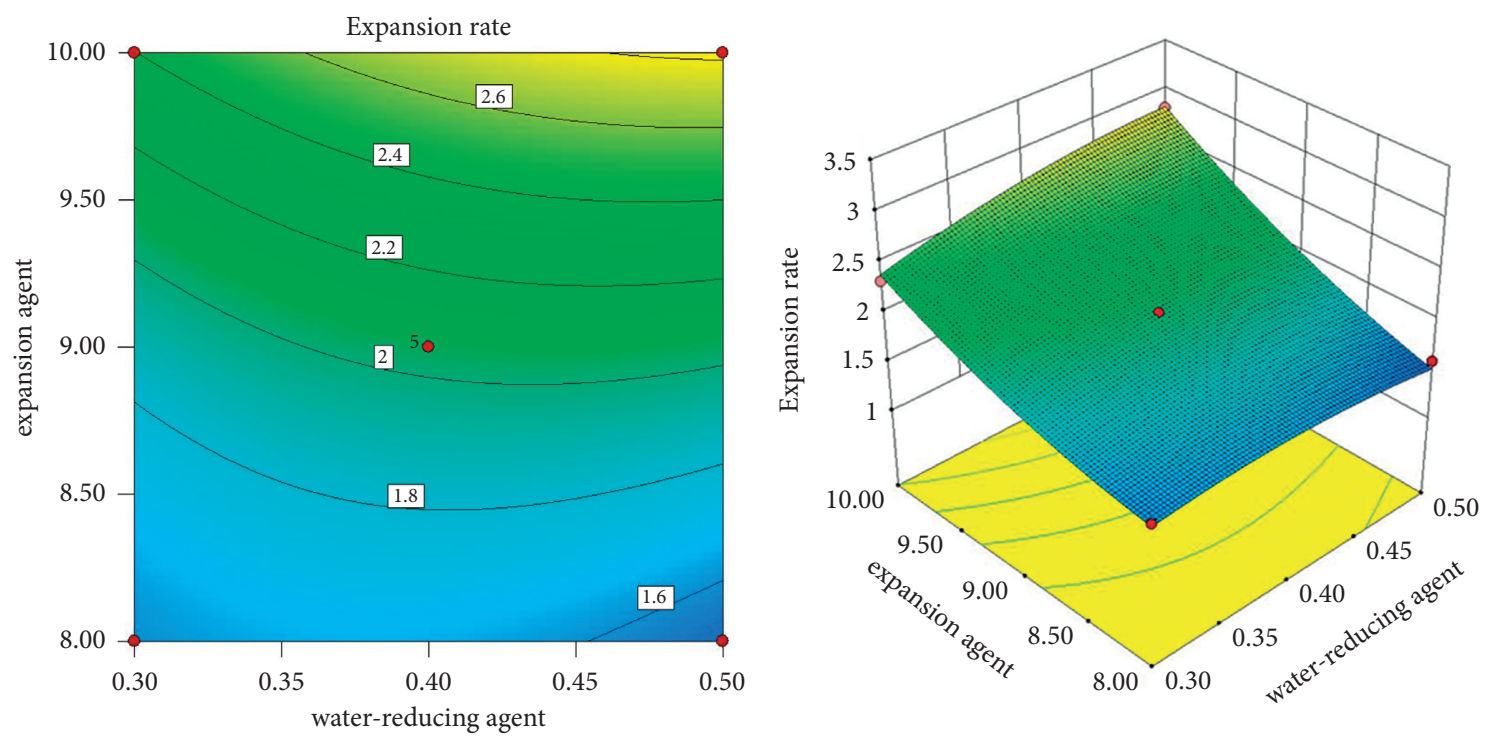

Figure 6: Effect of water-reducing agent $\mathrm{C}$ and expansion agent $\mathrm{D}$ on the expansion rate.
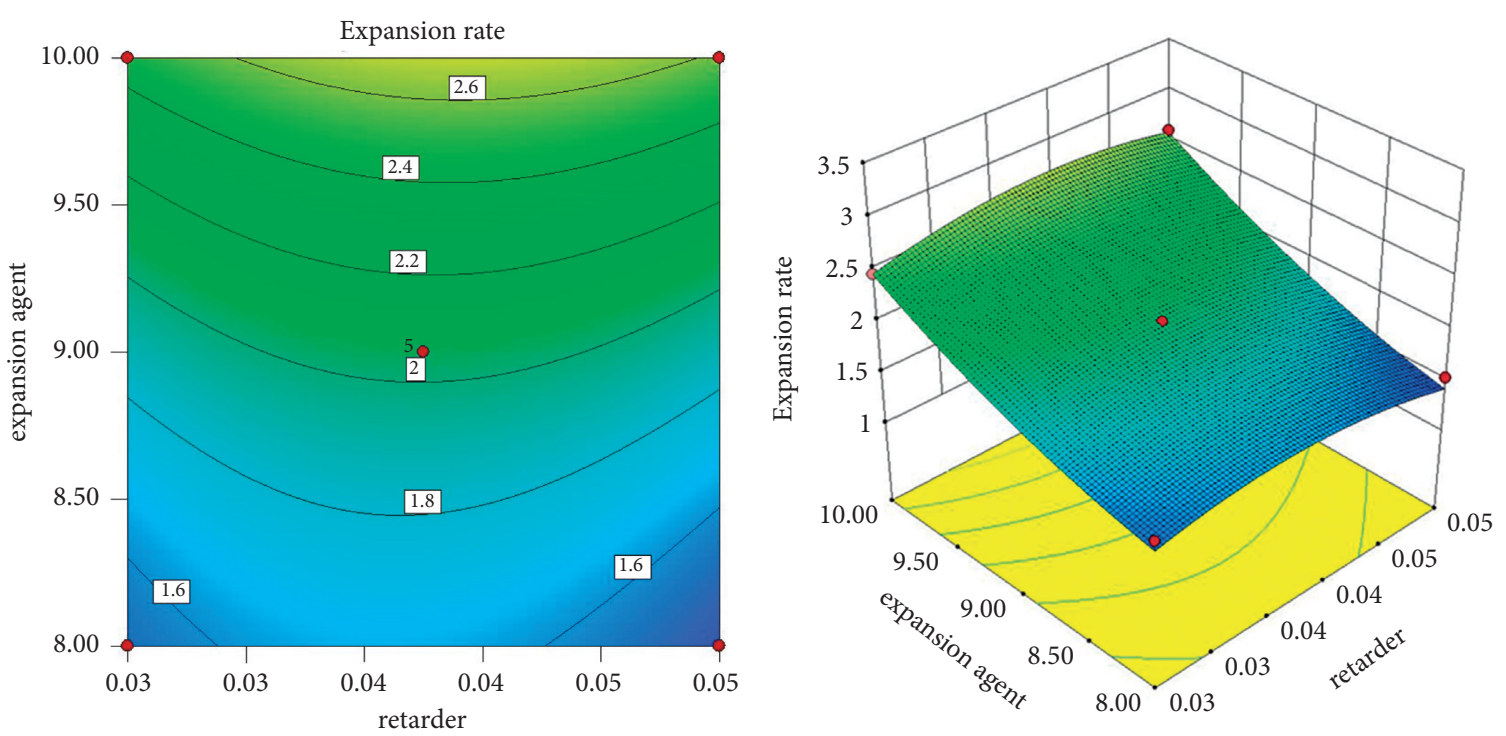

Figure 7: Effect of retarder $\mathrm{B}$ and expansion agent $\mathrm{D}$ on the expansion rate.

more significant influence on the response value than the water-reducing agent. The response surface is steep, indicating that the interaction between the two factors is obvious. When the values of water reducer and expansion agent reach the upper limit, the influence is the most significant.

Figure 7 shows the effect of retarder and expansion agent on the expansion rate. It can be seen that the ordinate contours are denser, indicating that the expansion agent has a higher effect on the expansion rate than the retarder, which is consistent with the results of the analysis of variance. When the value of the expansion agent is closer to the upper limit, the response surface is steeper, which shows that the interaction between the retarder and the expansion agent has a significant effect on the response value.
Figure 8 shows the effect of water-cement ratio and waterreducing agent on the expansion rate. It can be seen that the distributions of the ordinate contour and the abscissa contour are equivalent, showing that the effect of the water-cement ratio is close to that of the water-reducing agent on the response value. The contour distribution trend is related to the factor level, and the response surface graph has a certain distortion, which proves the certain interaction between the water-cement ratio and the water-reducing agent. However, the interaction between the two factors is weak, which is reflected in the small distortion of the surface graph.

Figure 9 shows the contours of the retarder and the water reducer are relatively sparse, and the response surface is relatively smooth, indicating that the two factors have a certain influence on the expansion rate, but the range of this influence is small. 

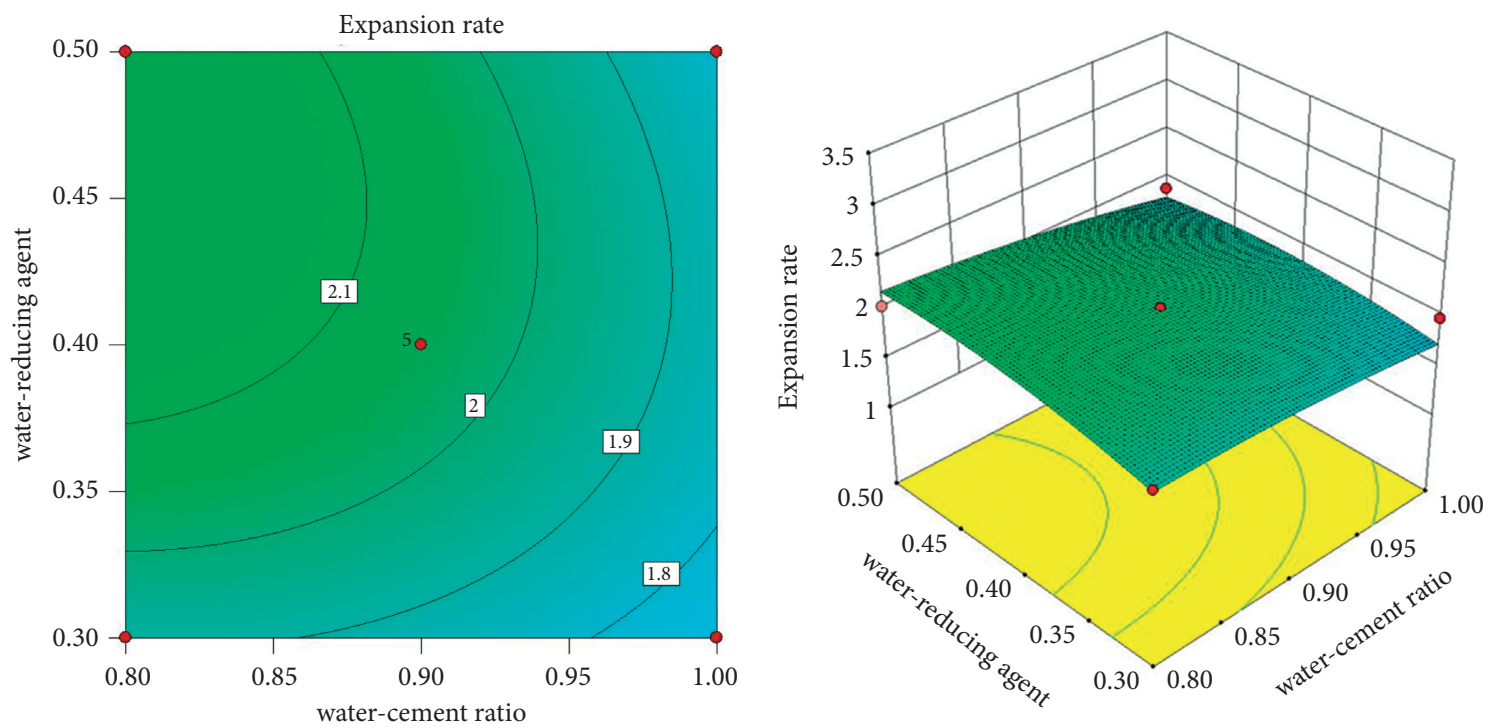

Figure 8: Effect of the water-cement ratio $\mathrm{A}$ and water reducer $\mathrm{C}$ on the expansion rate.
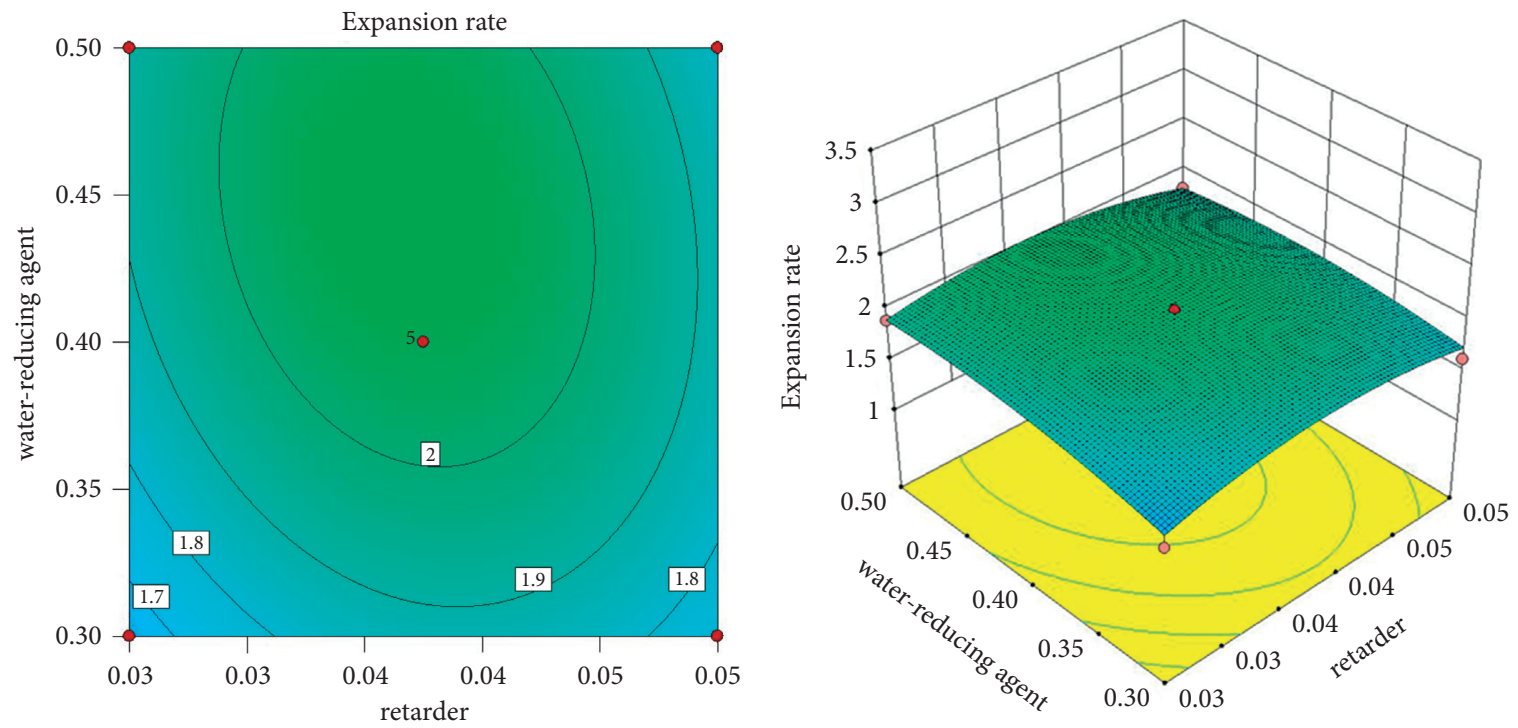

FIGURE 9: Effect of retarder $B$ and water reducer $C$ on the expansion rate.

Figure 10 shows the effect of the water-cement ratio and retarder on the expansion rate. It can be seen that the contours of water-cement ratio and retarder are sparse, and the response surface is relatively smooth, indicating that the two factors have a certain influence on the expansion rate, but the range of this influence is small, which is consistent with the results of the analysis of variance.

4.4. Parameter Optimization and Result Verification. The experimental results were further analyzed. The index was optimized with the expansion rate and the optimized experimental plan was obtained with the Design-Expert software. The first five groups of optimized experimental schemes were selected for verification, and the results are shown in Table 7.
It can be seen from Table 7 that, after the optimization of the ratio, the maximum absolute error between the predicted value of the material expansion rate and the actual measured value is only $1.601 \%$, indicating that the model is relatively reliable. Given the operability and simplicity of on-site grouting, comprehensive expansion rate, fluidity, and strength, the best experimental conditions were selected as the water-reducing agent content of $0.5 \%$, retarder content of $0.04 \%$, water-cement ratio of 0.8 , and expansion agent content of $10 \%$.

4.5. Micromorphology of Hydration Products. The micromorphology of the new sealing material at different curing ages is shown in Figure 11. It can be seen that, when curing for 3 days, there are flocculent C-S-H gels wrapping around 

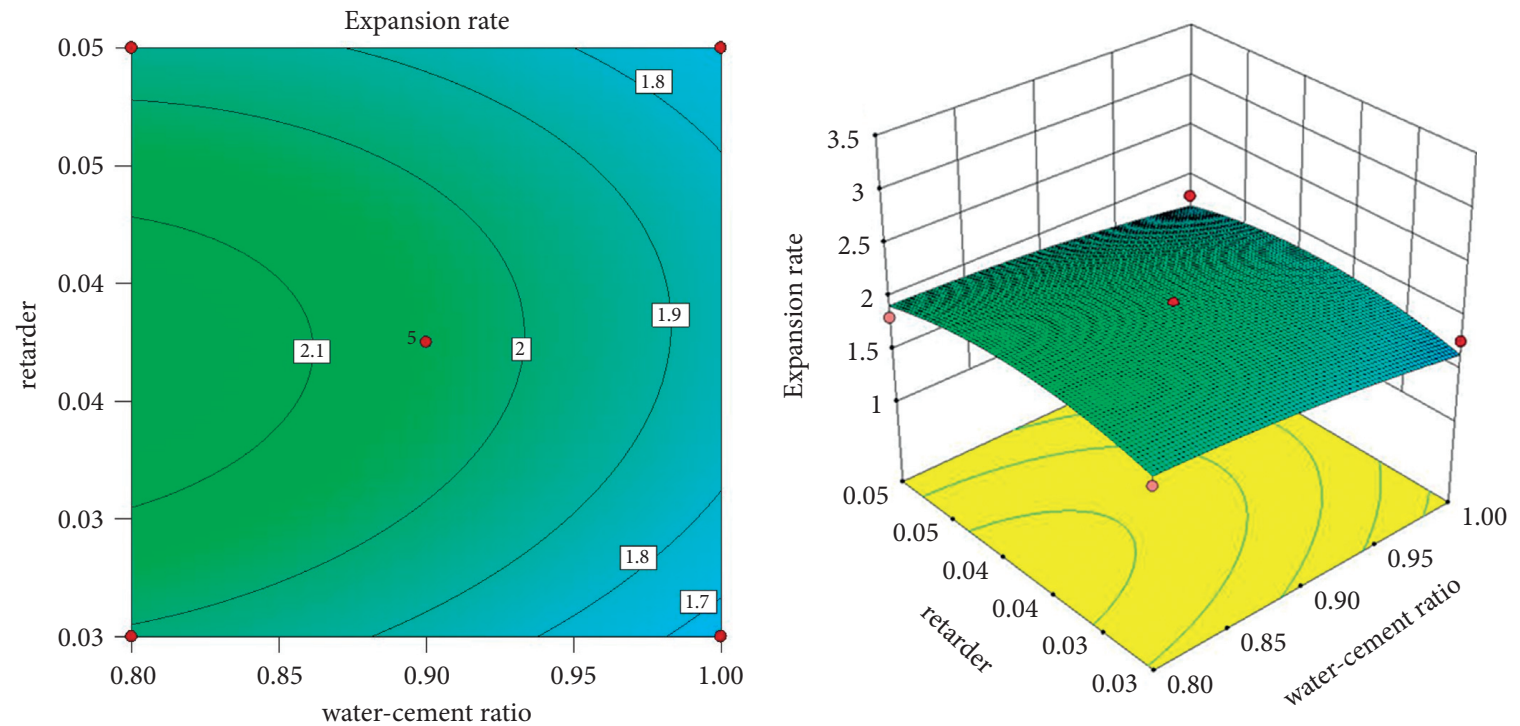

Figure 10: Effect of the water-cement ratio and retarder on the expansion rate.

TABLE 7: Optimum scheme and results.

\begin{tabular}{|c|c|c|c|c|c|c|c|}
\hline \multirow[b]{2}{*}{ No. } & \multirow[b]{2}{*}{$\begin{array}{l}\text { Water-cement } \\
\text { ratio }\end{array}$} & \multicolumn{3}{|c|}{ Experimental optimization ratio } & \multirow[b]{2}{*}{$\begin{array}{c}\text { Forecast expansion } \\
\text { rate } / \%\end{array}$} & \multirow[b]{2}{*}{$\begin{array}{c}\text { Measured expansion } \\
\text { rate } / \%\end{array}$} & \multirow[b]{2}{*}{$\begin{array}{c}\text { Error/ } \\
\quad \%\end{array}$} \\
\hline & & $\begin{array}{c}\text { Retarder/ } \\
\%\end{array}$ & $\begin{array}{c}\text { Water-reducing } \\
\text { agent } / \%\end{array}$ & $\begin{array}{c}\text { Expansion agent/ } \\
\%\end{array}$ & & & \\
\hline 1 & 0.8 & 0.04 & 0.5 & 10 & 3.18703 & 3.136 & -1.601 \\
\hline 2 & 0.8 & 0.04 & 0.49 & 10 & 3.17847 & 3.142 & -1.147 \\
\hline 3 & 0.8 & 0.04 & 0.5 & 9.95 & 3.13293 & 3.109 & -0.764 \\
\hline 4 & 0.82 & 0.04 & 0.5 & 10 & 3.12996 & 3.127 & -0.095 \\
\hline 5 & 0.84 & 0.04 & 0.48 & 10 & 3.0509 & 3.044 & -0.226 \\
\hline 6 & 0.8 & 0.03 & 0.44 & 9.91 & 2.92713 & 2.934 & 0.235 \\
\hline
\end{tabular}
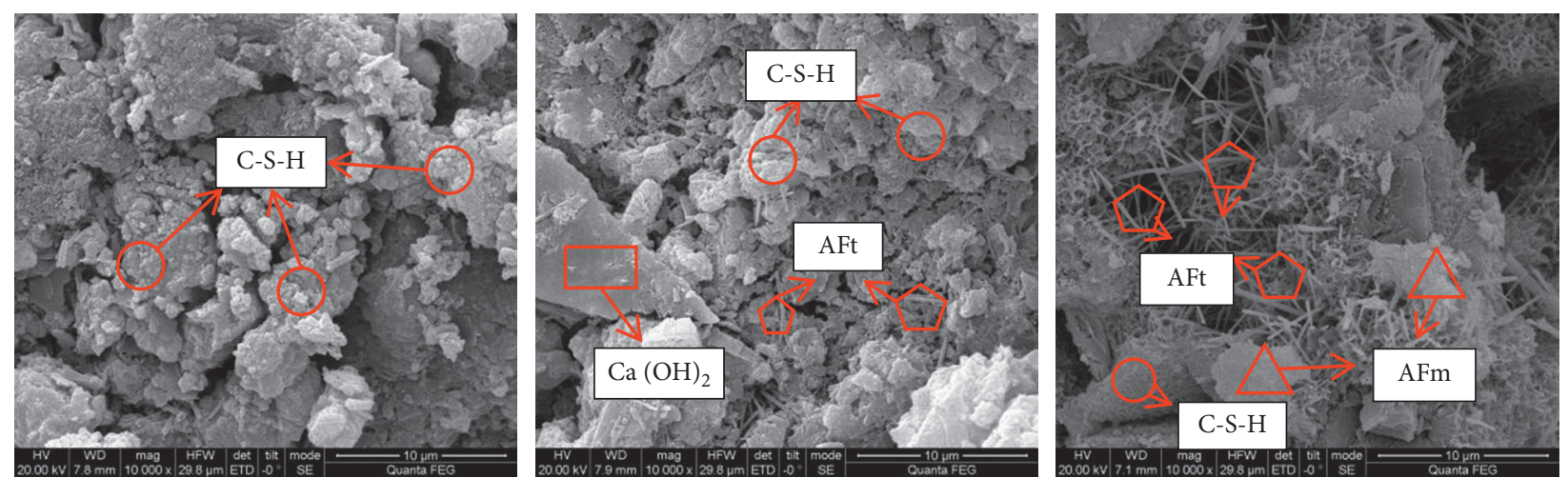

Figure 11: The micromorphology of the new material at different curing ages.

the cement particles, and a small amount of needle-shaped ettringite is generated. After curing for 7 days, the surface of cement particles is wrapped by hydration products and more ettringite is generated, which provides a certain strength for the material. After curing for 60 days, ettringite attached to the surface of cement particles is quite obvious, being longer and denser. A large flocculent C-S-H gel interacts with ettringite, which can absorb large amounts of water molecules and then cause the cement particles to repel each other, bringing more expansion.

\section{Conclusions}

(1) The influence of each component on the material expansion rate was tested by analysis of variance and significance test: D (expansion agent) $>$ A (water- 
cement ratio) $>\mathrm{C}$ (water-reducing agent) $>\mathrm{B}$ (retarder). According to the response surface drawn by the binomial polynomial regression equation, the interaction of any two factors to obtain the interaction law was analyzed: $\mathrm{AD}$ (water-cement ratio, expansion agent) $>\mathrm{CD}$ (water-reducing agent, expansion agent) $>\mathrm{BD}$ (retarder, expansion agent) $>\mathrm{AC}$ (water-cement ratio, water-reducing agent) $>\mathrm{BC}$ (retarder, water-reducing agent) $>\mathrm{AB}$ (watercement ratio, retarder).

(2) Ultrafine Portland cement is selected as the major ingredient and the expansion agent, water-reducing agent, and retarder were selected as the minor ingredients to produce a new kind of borehole sealing material. The optimal experimental conditions in this experiment were obtained by response surface analysis as water-reducing agent content of $0.5 \%$, retarder content of $0.04 \%$, water-cement ratio of 0.8 , and expansion agent content of $10 \%$, with an expansion rate reaching $3.136 \%$.

(3) The microstructures of the new materials are observed and analyzed. The amount of ettringite increases with the curing time. At $3 \mathrm{~d}$ hydration, a small amount of needle-shaped ettringite is generated. At $7 \mathrm{~d}$ hydration, more ettringite is generated, which provides a certain strength for the material. At $60 \mathrm{~d}$ hydration, almost no cement particles are observed in the hardened cement paste. A large amount of needle-shaped ettringite is produced on the surface of hydration products such as $\mathrm{C}-\mathrm{S}-\mathrm{H}$ gel and $\mathrm{Ca}(\mathrm{OH})_{2}$ to provide power for the expansion of the material.

\section{Data Availability}

The data used in the article can be obtained from the corresponding author.

\section{Conflicts of Interest}

The authors declare no potential conflicts of interest with respect to the research, authorship, and/or publication of this article.

\section{Authors' Contributions}

All the authors contributed to this paper. Xin Guo prepared and edited the manuscript. Sheng Xue and Yaobin Li made a substantial contribution to the data analysis and revised the article. Maoliang Shen and Yang Xu reviewed the manuscript and processed the results of numerical simulation during the research process. Chun-Shan Zheng provided the fund's support.

\section{References}

[1] L. Yuan, "Strategic thinking of simultaneous exploitation of coal and gas in deep mining," Journal of China Coal Society, vol. 41, no. 1, pp. 1-6, 2016.
[2] L. Yuan and P. S. Zhang, "Development status and prospect of geological guarantee technology for precise coal mining," Journal of China Coal Society, vol. 44, no. 8, pp. 2277-2284, 2019.

[3] C. A. Juarez, G. Fajardo, S. Monroy, A. Duran-Herrera, P. Valdez, and C. Magniont, "Comparative study between natural and PVA fibers to reduce plastic shrinkage cracking in cement-based composite," Construction and Building Materials, vol. 91, pp. 164-170, 2015.

[4] M. Wyrzykowski, P. Trtik, B. Münch, J. Weiss, P. Vontobel, and P. Lura, "Plastic shrinkage of mortars with shrinkage reducing admixture and lightweight aggregates studied by neutron tomography," Cement and Concrete Research, vol. 73, pp. 238-245, 2015.

[5] E. Boghssian and L. D. Wegner, "Use of flax fiber to reduce plastic shrinkage cracking in concrete," Cement and Concrete Composites, vol. 30, no. 10, pp. 929-937, 2008.

[6] F. Pelisser, A. B. d. S. S. Neto, H. L. L. Rovere, and R. C. d. A. Pinto, "Effect of the addition of synthetic fibers to concrete thin slabs on plastic shrinkage cracking," Construction and Building Materials, vol. 24, no. 11, pp. 21712176, 2010.

[7] T. J. Zhang, R. Y. Bao, S. G. Li, S. Zhang, L. Zhang, and K. Jiang, "Experimental study on expansion and creep characteristics of new CF sealing material," Journal of Mining \& Safety Engineering, vol. 36, no. 1, pp. 175-183, 2019.

[8] S. G. Li, J. F. Zhang, C. Zhang, and H. Yang, "Experimental study on expansion mechanism of new CF sealing material and the key influencing factors," Journal of Mining \& Safety Engineering, vol. 35, no. 2, pp. 415-421, 2018.

[9] J. Hogancamp and Z. Grasley, "The use of microfine cement to enhance the efficacy of carbon nanofibers with respect to drying shrinkage crack resistance of portland cement mortars," $\mathrm{Ce}$ ment and Concrete Composites, vol. 83, pp. 269-272, 2017.

[10] H. T. Wang, X. C. Wang, M. H. Zhai et al., "Experiment and application of new material for grouting of gangue based aquifer," Journal of China Coal Society, vol. 42, no. 11, pp. 2981-2988, 2017.

[11] Y. X. Liu, Y. Y. Chi, and W. Tian, "Effect of different expanders on properties of cement-based grouting," Material. Journal of Build Material, vol. 1-13, 2021, http://kns.cnki.net/ $\mathrm{kcms} /$ detail/31.1764.TU.20210514.1112.024.html.

[12] X. Ye, W. X. Wu, W. H. Hou, S. Lei, and Z. Zhou, "Influence of expansion agent on the volume stability of high-strength grouting materials," Journal of Building Materials, vol. 21, no. 6, pp. 950-955, 2018.

[13] C. Rossler, A. Eberhardt, H. Kucerova, and B. Moser, "Influence of hydration on the fluidity of normal Portland cement pastes," Cement and Concrete Research, vol. 38, no. 7, pp. 897-906, 2008.

[14] B. Mota, T. Matschei, and K. Scrivener, "The influence of sodium salts and gypsum on alite hydration," Cement and Concrete Research, vol. 75, pp. 53-65, 2015.

[15] J. J. Feng, P. Zhang, and W. Chen, "Self-healing behavior of early concrete cracks incorporating magnesium oxide expansive agent," Journal of Building Materials, vol. 21, no. 4, pp. 656-662, 2018.

[16] F. Z. Cao and P. Y. Yan, "Effect of water-binder ratio on hydration degree and expansive characteristics of magnesium oxide expansive agents," Journal of the Chinese Ceramic Society, vol. 47, no. 2, pp. 171-177, 2019.

[17] Z. Y. Liu, W. L. Bi, and Y. Guan, "Impact of expansive agent from calcined magnesite tailings on expansion performance of cement mortar," Journal of Building Materials, vol. 24, no. 3, pp. 466-472, 2021. 
[18] A. Zhou and K. Wang, "A new inorganic sealing material used for gas extraction borehole," Inorganic Chemistry Communications, vol. 102, pp. 75-82, 2019.

[19] H. C. Du, Y. N. Wang, M. M. He, Z. Lin, and Z. Lyu, "Study on the effect of organic retarder on the performance of cement modified emulsified asphalt mastic," Materials Review, vol. 33, no. S2, pp. 254-260, 2019.

[20] B. K. You and N. Z. Li, Expansive Agent and Shrinkage Compensating Concrete, China Building Materials Industry Press, Beijing, China, 2005.

[21] X. Yu, C. Yu, Q. P. Ran, and J. Liu, "Retarding mechanism of hydroxy carboxylic acid retarder on cement hydration," Journal of the Chinese Ceramic Society, vol. 46, no. 2, pp. 181-186, 2018.

[22] Y. Zhang and X. Kong, "Correlations of the dispersing capability of NSF and PCE types of superplasticizer and their impacts on cement hydration with the adsorption in fresh cement pastes," Cement and Concrete Research, vol. 69, no. 3, pp. 1-9, 2015.

[23] L. Shui, Z. Sun, H. Yang, X. Yang, Y. Ji, and Q. Luo, "Experimental evidence for a possible dispersion mechanism of polycarboxylate-type superplasticisers," Advances in Cement Research, vol. 28, no. 5, pp. 287-297, 2016. 